\title{
INDUCTION OF LABOUR WITH VAGINAL MISOPROSTOL IN INTRAUTERINE FOETAL DEATH
}

\section{Neeta Sarma ${ }^{1}$}

${ }^{1}$ Assistant Professor, Department of Obstetrics and Gynaecology, Silchar Medical College and Hospital.

ABSTRACT
BACKGROUND
Intrauterine foetal death is an unfortunate event met in obstetric practice. Misoprostol has emerged as an efficient and relatively
safe drug to deliver the baby in this condition. The objective of this study is to evaluate the safety and efficacy of vaginal
misoprostol tablets for the induction of labour in intrauterine foetal death.

\section{MATERIALS AND METHODS}

This uncontrolled clinical trial was performed on 100 women with intrauterine foetal death from January 2016 to December 2016 at Silchar Medical College and Hospital. All women were properly evaluated. Informed consent was taken and vaginal misoprostol tablets at a dose of $50 \mathrm{mcg} 4$ hourly was used to induce labour. The results were assessed.

\section{RESULTS}

In a study of 100 women, mean natural age was $26.21 \pm 4.98$ years, mean gestational age was $38.81 \pm 4.26$ weeks, $61 \%$ women were primigravida and the rest were multigravida; $80 \%$ were booked cases, $72 \%$ belonged to rural areas and $76 \%$ were illiterates. The mean initial Bishop's score was $2.23 \pm 1.82$ (range 0 to 6 ), while following induction with misoprostol the mean Bishop's score was $6.98 \pm 2.1$, the mean difference was 4.75 . P value was statistically significant. The mean induction-labour onset interval was $10 \pm 6.65$ hours and the mean induction-delivery interval was 13.60 hours with $46.46 \%$ women delivering within 12 hours. The mean misoprostol dose required was $152.5 \pm 88.5 \mathrm{mcg}$. Induction was successful in all women, but laparotomy was needed in 1 women because of uterine rupture. The side effects noted were nausea (7\%), vomiting (2\%), diarrhoea (4\%), fever (5\%), uterine hyperstimulation (4\%), ruptured uterus (1\%), retained placenta (3\%) and atonic post-partum haemorrhage (3\%).

\section{CONCLUSION}

Misoprostol is an effective, economic and safe drug that can be used for cervical ripening and labour induction in intrauterine foetal death. Clinical significance- the response to misoprostol is influenced by the gestational age, Bishop's score and parity of the women.

\section{KEYWORDS}

Vaginal Misoprostol, Intrauterine Foetal Death, Labour, Induction, Non-Randomised Interventional Prospective Study.

HOW TO CITE THIS ARTICLE: Sarma N. Induction of labour with vaginal misoprostol in intrauterine foetal death. J. Evolution Med. Dent. Sci. 2017;6(89):6192-6195, DOI: 10.14260/jemds/2017/1346

\section{BACKGROUND}

Intrauterine foetal death is a nightmare for a pregnant lady as well as her obstetrician. Left undisturbed the women usually go into spontaneous labour, but if a dead foetus is retained in the uterus for too long there is risk of developing sepsis and coagulation disorders coupled with mental trauma to the lady. Hence, induction of labour is often required. However, unlike in normal term pregnancy in patients with intrauterine foetal death the uterus is less sensitive to oxytocics, the cervix is usually not ripe and surgical methods of induction carries the risk of infection. Intravenous oxytocin has been used since ages but often large doses over prolonged duration are needed, particularly if the cervix is unfavourable leading to water intoxication. Condition of the cervix prior to induction is an important predictor of success of induction.

'Financial or Other Competing Interest': None.

Submission 07-10-2017, Peer Review 01-11-2017,

Acceptance 07-11-2017, Published 13-11-2017.

Corresponding Author:

Dr. Neeta Sarma,

Quarter No. 31,

Professor's Colony,

Silchar Medical College and Hospital,

Ghungoor, Silchar Dist., Cachar-788014,

Assam, India.

E-mail: sarma_neeta@rediffmail.com

DOI: $10.14260 /$ jemds $/ 2017 / 1346$

(c) $\underset{\mathrm{BY}}{\mathrm{NC} \mathrm{ND}}$
Therefore, medications that will reliably ripen the cervix in a short period of time play an important role in modern day obstetrics. Prostaglandins - PGE2 gel (intracervical) and PGE1 analogue misoprostol have been used for cervical priming and labour induction with high success rate. Misoprostol, a methylester of PGE1, is a potent uterotonic that can be administered by oral, vaginal, rectal and buccal routes. Vaginal administration has been found to be more effective than oral.1,2,3 In contrast to other prostaglandins, misoprostol is selective for the uterus and has no significant effect on the bronchi or blood vessel. Side effects like nausea, diarrhoea and fever are infrequent and dose related. Its safety, cost effectiveness, long shelf-life and ease of administration makes it ideal for low-resource settings. ${ }^{4}$ In recent years, there has been a considerable interest in the use of misoprostol ${ }^{5,6,7}$ for cervical ripening and labour induction. With this background information, the current trial was designed to evaluate the safety and efficacy of misoprostol tablet when used vaginally for induction of labour in intrauterine foetal death with special emphasis on the induction delivery interval, the mode of delivery, the success rate of the drug in labour induction and the incidence of side effects and complications.

\section{MATERIALS AND METHODS}

This uncontrolled clinical trial was carried out in the Department of Obstetrics and Gynaecology, Silchar Medical College and Hospital (SMCH) over a period of one year from 
January 2016 to December 2016 and was approved by the local Institute of Ethical Committee. 100 women aged 18 - 40 years including primigravida and multigravida (upto gravida 3 ) with gestational age beyond 28 weeks having single dead foetus in cephalic presentation with membranes intact or ruptured were included in the trial. Women excluded from the study included those with hypersensitivity to prostaglandins, those with history of liver disease, glaucoma, convulsive disorder, those with scarred uterus due to previous caesarean section or myomectomy and those with placenta praevia. Each woman was properly evaluated by detailed history taking and thorough clinical examination and diagnosis was confirmed by ultrasonography. The purpose and procedure of induction, the advantages and the possible risks were well explained to the woman and her attendant and a written and informed consent was taken. All patients were investigated and the Bishop's score was assessed. Tablet misoprostol $50 \mathrm{mcg}$ vaginally in posterior fornix was used four hourly till the patient went into active labour or upto a maximum dose of $400 \mathrm{mcg}$. Active labour was diagnosed when the cervix was $3 \mathrm{~cm}$ dilated or uterine contractions were 3 in 10 minutes, each lasting at least 40 seconds. The induction was categorised as having failed if the woman did not go into labour even after 4 hours of the eighth dose. The patient was thereafter augmented with oxytocin by escalation method or considered for caesarean section as required. Progress of labour was assessed by noting the frequency, duration and strength of painful uterine contractions half hourly, the rate of cervical dilatation and head descent three hourly and complications were dealt with symptomatically. Uterine hyperstimulation was said to occur if uterine contractions were $\geq 5$ in 10 minutes, each lasting $\geq 90$ seconds and was managed by removal of tablet from the vagina if possible or administration of uterine relaxants like nifedipine $10 \mathrm{mg}$ sublingual or injection terbutaline $250 \mathrm{mcg}$ subcutaneously. During the course, injection tramadol $100 \mathrm{mg}$ intramuscular or injection promethazine $25 \mathrm{mg}$ intramuscular was used in the early stages of labour for analgesia if felt necessary. After delivery, the woman was observed throughout the hospital stay for any complications.

The main measure of efficacy was success rate of induction. Other measures were total dose of misoprostol required, induction - labour onset interval, rate of cervical dilatation, duration of labour, induction - delivery interval, need for oxytocin augmentation and analgesia, mode of delivery, any operative procedure required, side effects and complications. Baseline characteristics noted were maternal age, pregnancy duration, parity, socioeconomic status and pre-induction cervical score.

\section{Statistical Analysis}

Appropriate statistical analysis was done with the help of SPSS version 20. Data analysis was done by unpaired student's ' $\mathrm{t}$ ' test and $\mathrm{P}$ value $<0.05$ was considered significant.

\section{RESULTS}

The observations that were noted from the study have been tabulated. A total of 100 women with intrauterine foetal death admitted in the Obstetrics and Gynaecology Department, $\mathrm{SMCH}$, were taken up for the study.
As seen in Table 1, majority of the cases (60\%) were in the age range of 18 to 25 years. $61 \%$ of them were nulliparous. The cases were mostly unbooked $(80 \%)$, hailing from rural areas (72\%) and illiterates (76\%). $46 \%$ were of term pregnancy, the mean gestational age being $38.81 \pm 4.26$ weeks. Baseline Bishop's score ranged from 0 to 6 , maximum (61\%) had a score of 0 to 2 .

There was significant change in the Bishop's score (Table 2) following labour induction.

Table 3 shows the total dose of misoprostol required ranged from $50 \mathrm{mcg}$ to $350 \mathrm{mcg}$. The mean total dose required was $152.5 \pm 88.5 \mathrm{mcg}$. The induction - labour onset interval ranged from 2 hours to 25 hours, the mean being $10 \pm$ 6.65 hours. The induction delivery interval ranged from 3 hours 40 minutes to 38 hours 30 minutes, the mean being 13.66 hours.

The mean total dose requirement, the mean induction labour onset interval and the mean induction - delivery interval was found to decrease with increase in pregnancy duration, parity and increasing Bishop's score. The duration of first stage of labour was inversely and the cervical dilatation rate was directly related to the gestational age, Bishop's score and parity.

Induction was successful (Table 4) in all cases. But vaginal delivery occurred in $99 \%$ cases and in $1 \%$ case laparotomy was needed due to uterine rupture.

Side effects (Table 5) like nausea, fever and diarrhoea were related to higher doses of misoprostol. Retained placenta was seen in $3 \%$ cases and were related to multiparity and lower gestational age. Atonic PPH was seen in $3 \%$ cases and all the cases were multiparous.

\begin{tabular}{|c|c|c|}
\hline Variables & Mean \pm S.D & Frequency \\
\hline Age (years) $^{\mathrm{a}}$ & $26.21 \pm 4.98$ & \\
Gestational age (week) $^{\mathrm{a}}$ & $38.81 \pm 4.26$ & Multi 39\% \\
Paritya $^{\mathrm{a}}$ & & Primi $61 \%$ \\
Socio-economic status $^{\mathrm{a}}$ & & Booked $20 \%$ \\
& & Unbooked $80 \%$ \\
& & Urban $28 \%$ \\
& & Rural $72 \%$ \\
& & Literate $24 \%$ \\
Initial Bishop's Score & & Illiterate $76 \%$ \\
\hline \multicolumn{2}{|c|}{ Table 1. Demographic Characteristics of All Cases } \\
\hline
\end{tabular}

aStudent's ' $t$ ' test- Data represented as mean \pm S.D or $\%$

\begin{tabular}{|c|c|c|c|}
\hline $\begin{array}{c}\text { Mean } \\
\text { Bishop's } \\
\text { before } \\
\text { Induction }\end{array}$ & $\begin{array}{c}\text { Mean } \\
\text { Bishop's } \\
\text { after } \\
\text { Induction }\end{array}$ & $\begin{array}{c}\text { Mean } \\
\text { Difference }\end{array}$ & P Value \\
\hline $2.23 \pm 1.82$ & $6.98 \pm 2.1$ & 4.75 & 0.0001 \\
\hline \multicolumn{3}{|c|}{ Table 2. Change in Bishop's Score } \\
\hline
\end{tabular}

$P$ value is significant. Student's ' $t$ ' test, data represented as mean \pm S.D. 


\begin{tabular}{|c|c|}
\hline Outcome & Range/ Frequency \\
\hline (hours) & $10 \pm 6.65(2-25)$ \\
Induction-delivery interval (hours) & $13.60(3.66-38.50)$ \\
$<12$ hours (\%) & 46.46 \\
$12-24$ hours (\%) & 42.43 \\
$>24$ hours (\%) & 10.11 \\
Dose of misoprostol (mcg) & $152.5 \pm 88.5(50-350)$ \\
50 mcg (\%) & 19 \\
100 mcg (\%) & 29 \\
150 mcg (\%) & 22 \\
$\geq 200$ mcg (\%) & 30 \\
Need for oxytocin augmentation (\%) & 35 \\
Analgesia requirement (\%) & 34 \\
Duration of labour & \\
First stage (hours) & $3.3 \pm 1.8(1.25-12.56)$ \\
Second stage (minutes) & $39.29 \pm 19.56(10-100)$ \\
Third stage (minutes) & 6.89 \\
Rate of cervical dilatation (cm/ hour) & $2.12 \pm 0.93(0.54-5.60)$ \\
\hline
\end{tabular}

\section{Table 3. Intrapartum Variables}

Student's ' $\mathrm{t}$ ' test- data represented as mean \pm S.D or $\%$

\begin{tabular}{|c|c|c|}
\hline Outcome & Number of Cases & $\mathbf{\%}$ \\
\hline Successful induction & 100 & 100 \\
Mode of delivery & & \\
Vaginal & 99 & 99 \\
Abdominal (laparotomy) & 1 & 1 \\
\hline \multicolumn{2}{|c|}{ Table 4. Success of Induction and Delivery Method } \\
\hline
\end{tabular}

\begin{tabular}{|c|c|}
\hline Variables & Percentage of Cases \\
\hline Nausea & 7 \\
Vomiting & 2 \\
Diarrhoea & 4 \\
Fever & 5 \\
Uterine hyperstimulation & 4 \\
Ruptured uterus & 1 \\
Retained placenta & 3 \\
Atonic PPH & 3 \\
\hline Table 5. Side Effects and Maternal Complications \\
\hline
\end{tabular}

\section{DISCUSSION}

In our study $60 \%$ women were in the age group of $18-25$ years, $61 \%$ were primigravida, while the rest were gravida 2 or 3; $46 \%$ were of term pregnancy. The initial Bishop's score ranged from 0 to 6 with $61 \%$ having a score of 0 to 2 .

In the study by Easmin S et al, $846 \%$ belonged to the age group 18 - 25 years, $80 \%$ had gestational age of $28-37$ weeks, $64 \%$ had the initial Bishop's score of 0 to 3 and the rest 4 to 6 . In the study by Sharma D et al, ${ }^{9} 50 \%$ were of term pregnancy.

In our study, 50 mcg misoprostol was used vaginally four hourly till the onset of active labour or a maximum dose of $400 \mathrm{mcg}$ and the mean total dose used was $152.5 \pm 88.5 \mathrm{mcg}$. The optimal dosage regimen of misoprostol and the frequency of administration has not yet been determined.

El Gharib et al ${ }^{10}$ have used 25 mcg four hourly over 24 hours with a mean total dose of $120 \pm 28.79 \mathrm{mcg}$. Panda S et al ${ }^{11}$ have used $100 \mathrm{mcg}$ four hourly, the maximum dosage being $600 \mathrm{mcg}$ in 24 hours; Sharma et $\mathrm{al}^{9}$ have used $100 \mathrm{mcg}$ and 50 mcg misoprostol every 3 hourly in pregnancies less than 37 weeks and beyond 37 weeks respectively till the beginning of active labour or a maximum of 4 doses, whereas Easmin $\mathrm{S}$ et $\mathrm{al}^{8}$ have used $50 \mathrm{mcg}$ every 4 hourly upto effective contractions or a maximum of 6 doses.

Our study has showed a $100 \%$ success rate of induction. El Gharib et $\mathrm{al}^{10}$ has recorded $90 \%$ and $45 \%$ success rate in the third and second trimester foetal deaths respectively. Chaudhari $\mathrm{P}$ et $\mathrm{al}^{12}$ have achieved $92.5 \%$ and $71.2 \%$ success rates in their study which compared use of misoprostol with or without mifepristone respectively. $\mathrm{P}$ value being 0.001 , which was significant. A $98 \%$ success rate of induction was shown by Easmin $\mathrm{S}$ et $\mathrm{al},{ }^{8}$ whereas Dodd et $\mathrm{al}^{13}$ have noted comparable rates of vaginal delivery within 24 hours with a similar induction to birth interval in their assessment comparing vaginal misoprostol with other prostaglandin preparations.

The mean induction - delivery interval noted in our study was 13.66 hours and it was found to correlate negatively with pregnancy duration, parity and initial Bishop's score. El Gharib et $\mathrm{al}^{10}$ had shown induction delivery interval of $8.95 \pm$ 2.63 hours, which decreased with increasing duration of gestation.

Chaudhari $\mathrm{P}$ et al ${ }^{12}$ in their study had found induction delivery interval of $9.8 \pm 4.4$ hours and $16.3 \pm 5.7$ hours with or without the use of mifepristone along with misoprostol respectively. $\mathrm{P}$ value being $<0.001$, which was significant. Easmin $\mathrm{S}$ et $\mathrm{al}^{8}$ has obtained a mean induction delivery interval of 11.8 hours ( 6 to 23 hours), whereas Sharma D et $\mathrm{al}^{9}$ have shown it to be $11.81 \pm 6.33$ hours and $6.72 \pm 3.34$ hours without or with the combined use of mifepristone with misoprostol respectively. Parity, gestational age and Bishop's score did not affect the induction- delivery interval in the study by Sharma D et al. ${ }^{9}$

In our study $35 \%$ required oxygen augmentation, whereas El Gharib et al ${ }^{10}$ has shown oxygen requirement in $55 \%$ women undergoing induction in third trimester foetal death. Agrawal $\mathrm{A}$ et $\mathrm{al}^{14}$ and Panda et $\mathrm{al}^{11}$ in their studies have shown oxytocin requirement in those women where misoprostol alone was used as compared to those where mifepristone was used as well.

Analgesic requirement was noted in $34 \%$ of the study population, which was comparable to the studies by Nyende et $\mathrm{al}^{3}$ which was $35.5 \%$ and De Heus et al ${ }^{15}$ which was $32.8 \%$.

The side effects and complications of using vaginal misoprostol in the present study and in other studies like Chittacharoen et al, ${ }^{16}$ Nyende et al, ${ }^{3}$ De Hues et al, ${ }^{15}$ Ezechi et $\mathrm{al}^{14}$ Dodd et $\mathrm{al}^{13}$ and Easmin et $\mathrm{al}^{8}$ included nausea, diarrhoea, vomiting, pyrexia, retained placenta, postpartum haemorrhage and hyperstimulation syndrome. Diarrhoea and elevated temperature were found to increase with increasing dose of misoprostol in the present study and the study by Dodd et al. ${ }^{13}$

\section{CONCLUSION}

Intrauterine foetal death is a rather unwanted, yet invariably encountered situation. Misoprostol is a very effective drug for induction of labour, as it has the dual property of cervical ripening and initiating uterine contractions and can be used at all gestational ages. Although the optimal dosing has not yet been determined, use of higher doses at frequent intervals for cases with lesser gestational age, poorer cervical score or 
lesser parity and vice versa should usually serve the purpose of bringing about successful induction and also avoiding unwanted complications. Given the possible complications inherent in the induction of labour, a specific signed informed consent should be mandatory and there should be institutionspecific practice guidelines and protocols to guide dosing and dose scheduling and careful chart documentation of all relevant outcomes whenever misoprostol is administered.

Compliance with ethical requirements and conflicts of interest- The study is in compliance with ethical standards. Permissions have been sought and is approved by the Institutional Ethical Committee.

\section{REFERENCES}

[1] Patrick J, David E, Christian S, et al. Misoprostol in Obstetrics and Gynaecology - summary of evidence. http://www.microprostol.org/misoprostolevidence.ht ml 2004-06-10.

[2] Fiala C, Safar P, Weeks A, et al. Misoprostol use in Obstetrics and Gynaecology. http://www.microprostol.org/downloads/microprost ol.africa.pdf 2004-05-25.

[3] Nyende L, Towobola OA, Mabina MH. Comparison of vaginal and oral misoprostol, for the induction of labour in women with intra-uterine foetal death. East Afr Med J 2004;81(4):179-82.

[4] Ezechi OC, Kalu BKe, Ndububa VI, et al. Induction of labour by vaginal misoprostol for intrauterine fetal death. J Obstet Gynecol Ind 2004;54(6):561-3.

[5] Wing DA, Paul RH. A comparison of differing dosing regimen of vaginally administered misoprostol for preinduction cervical ripening and labour induction. Am J Obstet Gynecol 1996;175(1):158-64.

[6] Sanchez-Ramos L, Peterson DE, Derke I, et al. Labour induction with prostaglandin E1 misoprostol compared with dinoprostone vaginal insert: a randomized trial. Obstet Gynecol 1998;91(3):401-5.

[7] Nunes F, Rodrigues R, Meirinho M. Randomized comparison between intra vaginal misoprostol and dinoprostone for cervical ripening and induction of labor. Am J Obstet Gynecol 1999;181(3):626-9.
[8] Easmin S, Nahar K, Jahan MK, et al. Intra-vaginal use of misoprostol for induction of labour in intrauterine death. Mymensingh Med J 2011;20(4):566-9.

[9] Sharma D, Singhal SR, Poonam, et al. Comparison of mifepristone combination with misoprostol and misoprostol alone in the management of intrauterine death: condensation - misoprostol and mifepristone combination is more effective than misoprostol alone in the management of intrauterine death. Taiwan J Obstet Gynaecology 2011;50(3):322-5.

[10] El-Gharib MN, Elebyary MT. Low-dose vaginal misoprostol in the management of intrauterine fetal death. J Matern Fetal Neonate Med 2011;24(10):123942.

[11] Panda S, Jha V, Singh S. Role of combination of mifepristone and misoprostol versus misoprostol alone in induction of labour in late IUFD: a prospective study. J Family Report Health 2013;7(4):177-9.

[12] Chaudhari P, Datta S. Mifepristone and misoprostol compared with misoprostol alone for induction of labour in intrauterine fetal death : a randomized trial. J Obstet Gynaecol Res 2015;41(12):1884-90.

[13] Dodd JM, Crowther CA. Misoprostol for induction of labour to terminate pregnancy in the second or third trimester for women with a fetal anomaly or after intra uterine fetal death. Cochrane Database Syst Rev 2010;(4):CD004901.

[14] Agrawal A, Basnet P, Thakur A, et al. Induction of labour using misoprostol with or without mifepristone in IUD. J Nepal Med Assoc 2014;52(194):781-6.

[15] De Heus R, Graziosi GC, Christiaens GC, et al. Medical management for termination of second and third trimester pregnancies: a comparison of strategies. Eur J Obstet Gynecol Reprod Biol 2004;116(1):16-21.

[16] Chittacharoen A, Herabutya Y, Punyavachira P. A randomized trial of oral and vaginal misoprostol to manage delivery in case of fetal death. Obstet Gynecol 2003;101(1):70-3. 